\title{
THE SOCIAL FIELD DESIGNED BY ARCHITECTURE
}

\author{
Author(s) / Auteur(s) : \\ Gianfranco Minati \\ Italian Systems Society, Milan \\ gianfranco.minati@,AIRS.it
}

\begin{abstract}
/résumé :
In the literature disciplinary researches, e.g., physics, studied the behaviour of elements, such as particles, in a context provided with properties, e.g., electromagnetic and gravitational. This context is classically considered as field, i.e., a physical quantity associated to each point of space-time. Social sciences and psychology use the concept of Force Field introduced by the social psychologist Kurt Lewin (1890-1947) The Force Field or life space was assumed to be -in any individual or social group-changing with experience and intended as representation of the environment, personal values, emotions and goals. We may say the cognitive system combined with representations and stimuli of the environment. This short essay focuses on Architecture as design of structures able to represent and induce properties of the cognitive systems possessed by inhabitants as well their transformation processes relating to social processes in progress. The subject is studied by Environmental Psychology, in the conceptual framework of Space Syntax. On one hand, the structure of space created through Architecture both represents and induces the social field within which inhabitants behave. On the other hand, inhabitants behave by using such a social field. Within this conceptual framework we may hypothesise the existence of a process of self-architecture by social systems. We explore the coherence, in such social fields, between different aspects such as architecture, design, fashion, music and painting.
\end{abstract}

Keywords / Mots-clés :

autonomous agent, coherence, environment, field, properties, social field

\section{THE CONCEPT OF FIELD}

In the literature disciplinary researches, e.g., physics, studied the behaviour of elements, such as particles, in a context provided with properties, e.g., electromagnetic and gravitational. This context is classically considered as field, i.e., a physical quantity associated to each point of space-time, see, for instance, Landau and Lifshitz (1971).

This area of research had subsequent important evolution over time by considering, for instance, the hypothesis of the unified field theory which aimed to write fundamental forces and elementary particles in terms of a single field, the three body problem, collective behaviours, and to introduce the Quantum Field Theory (QFT), see, for instance, Peskin and Schroeder (1995).

\section{NON AUTONOMOUS AGENTS}

The approaches and ideas come by considering non autonomous elements like particles and planets. The term non-autonomous, in contrast with autonomous elements introduced later, refers to the fact that they do possess properties, such as mass, magnetic and gravitational characteristics, and their behaviour is due to forces produced by 1) interaction between elements (e.g. due to collisions and magnetism), 2) properties (such as gravitational and magnetic properties,) associated to each point of space-time, specified by a field. 


\section{PROPERTIES OF THE CONTEXT}

When exploring the behaviour of certain elements, not only their properties and the field should be taken into account, but also the context in which these elements interact.

The Properties of contexts may interfere with forces establishing the elements' behaviour by altering intensity or by adding vectorial components due, for instance, to high, low or non-uniform, temperature, e.g., magnetisation and Bénard Rolls, and perturbations such as radiations.

Other properties of the context such as the geometrical features and topological location of a container setting the degrees of freedom to the behaviour assumed by elements, might be considered as well.

An example is given by the shape of pipelines where the movement acquired by elements thanks to a suitable field is converted into a flux having the dimension of the pipeline, e.g., grains of sand falling into a funnel.

\section{AUTONOMOUS ELEMENTS OR AGENTS}

Another related conceptual problem arises when we consider autonomous elements or autonomous agents. Their behaviour is established not only by considering the combination of their properties (the field in which they are immersed and the ones of the context as in the case of non-autonomous elements, i.e., their behaviour can be computed), but by the processing performed by their cognitive system since single formal models are not sufficient to represent their whole behaviour.

Autonomous systems are provided by a cognitive system intended as a system of cognitive abilities meant, for instance, to make logical inferences, memorise, make representations, hypothesise, use language and semantics, process emotions, learn, evolve, and take decisions.

Cognitive models are ways to process, for instance, information, representations and memories in order to perform an action. Cognitive systems are typical of complex living systems. Artificial cognitive systems able to perform partial activities have also been introduced, such as playing games, learning, allowing visual and voice recognition, and simulation. This is represented in the field of Artificial Intelligence by using the so-called sub-symbolic computing for instance in Neural Networks (NNs), Cellular Automata (CAs) and Genetic Algorithms (GAs). In the later cases cognitive models are intended as software programs. We highlight how the behaviour of autonomous agents results from combining properties of non-autonomous agents and cognitive processing. For instance, living beings all behave in the gravitational field combined with environmental factors such as temperature. However their behaviour is not the linear resultant of this combination since cognitively processed.

\section{SOCIAL FIELDS}

Social sciences and psychology use the concept of Force Field introduced by the social psychologist Kurt Lewin (1890-1947)( see, for instance, Lewin, 1935; 1936; 1951) in the framework of the Gestalt Psychology founded by Max Wertheimer, Wolfgang Köhler and Kurt Koffka (Koffka, 1935). The Force Field or life space was assumed to be -in any individual or social group- changing with experience and intended as representation of the environment, personal values, emotions and goals. We may say the cognitive system combined with representations and stimuli of the environment.

\section{ARCHITECTURE AND SOCIAL FIELDS}

Several studies and approaches introduced in the last years, see for instance, Batty (2005), Diappi (2004), Marshall (2008), Hensel et al. (2004) and Weinstock (2010), explore the social impact and significance of Architecture. This short essay focuses on Architecture as design of structures able to represent and induce properties of the cognitive systems possessed by inhabitants as well their transformation processes relating to social processes in progress; see, for instance, Minati and Collen (2009).

In this conceptual framework functionalities and rational aspects (e.g., economical, environmental, military and political) are of 'secondary' importance in the long range compared to architectural properties representing social cognitive properties such as attention to details; beauty; induction to 
meet; sense of hierarchy; multiplicity vs. standardisation; openness due to opening doors rather lack of concrete boundaries; topologies with labelled areas corresponding to values; usage of building material indicative of the social status of inhabitants; use of the territory in a non-optimised way, i.e., dedicated to green areas, playground and artistic exhibitions; usage of city lights, traffic lights and opening hours of shops to set social rhythms; systems of garbage collection as information; colour of the façade and their state being indicative of maintenance and attention to harmony with the architectural style of the neighbourhood etc., see, for instance, Collen (2009), Di Battista (2009), Fontana (2010) and Giallocosta (2010). The subject is studied by Environmental Psychology, researching topics such as the connection between broken windows and the study of crime prevention through environmental design in the conceptual framework of Space Syntax such as to the Space Syntax Laboratory, see web resource at the references, and, for instance, Cozens et al. (2005).

\section{COHERENCE}

On one hand, the structure of space created through Architecture both represents and induces the social field within which inhabitants behave. On the other hand, inhabitants behave by using such a social field. Within this conceptual framework we may hypothesise the existence of a process of selfarchitecture by social systems. We explore the coherence, in such social fields, between different aspects such as architecture, design, fashion, music and painting.

Metaphorically speaking we could say that Architecture provides the words by which social systems formulate sentences about their identity, about how they are changing and what kind of evolution they are aiming for.

The aim of this short contribution is to study and model, using an interdisciplinary approach, the coherence of the social field represented and created by architecture using suitable research methods, educational and professional activities, always baring in mind this complex network of interdependences.

\section{REFERENCES}

BATTY, M. (2005). Cities and Complexity Understanding Cities with Cellular Automata, Agent Based Models, and Fractals: Understanding Cities with Cellular Automata, Agent-Based Models, and Fractals. Cambridge: Massachusetts Institute of Technology

COLLEN, A. (2009). Emergence of Architectural Phenomena in the Human Habitation of Space, In: Proceedings of the Fourth National Conference of the Italian Systems Society (AIRS), Processes of emergence of systems and systemic properties. Towards a general theory of emergence (Minati G., PESSA E. and ABRAM M, eds.), World Scientific, Singapore, pp. 51-66.

DI BATTISTA, V. (2009). Environment and Architecture - A Paradigm Shift, In: Proceedings of the Fourth National Conference of the Italian Systems Society (AIRS), Processes of emergence of systems and systemic properties. Towards a general theory of emergence (Minati G., Pessa E. and Abram M, eds.), World Scientific, Singapore, pp. 37-49

DIAPPI, L. (2004). Evolving Cities. Aldershot: Ashgate Publishing.

FONTANA, G. (2010). Re-tracing the systemic approach in architecture and developing working tools, to be published in: Proceedings of the Fifth National Conference of the Italian Systems Society (AIRS), Methods, Models, simulations and approaches towards a general theory of change, (G. Minati, M. Abram and E. Pessa, eds.), World Scientific, Singapore.

GIALlOCOSTA, G. (2010). Architecture and Development of and within Social Systems, to be published in: Proceedings of the Fifth National Conference of the Italian Systems Society (AIRS), Methods, Models, simulations and approaches towards a general theory of change, (G. Minati, M. Abram and E. Pessa, eds.), World Scientific, Singapore.

HENSEL, M., MENGES, A., WEINSTOCK, M., eds. (2004). Emergence: Morphogenetic Design Strategies, Architectural Design, Vol. 74 No. 3, London: Wiley Academy.

KOFFKA, K. (1935). Principles of Gestalt Psychology. London: Lund Humphries. 
LANDAU, Lev D. and LIFSHITZ, Evgeny M. (1971). Classical Theory of Fields (3rd ed.). London: Pergamon. Vol. 2 of the Course of Theoretical Physics.

LEWIN, K. (1935). A dynamic theory of personality. New York: McGraw-Hill.

LEWIN, K. (1936). Principles of topological psychology. New York: McGraw-Hill.

LEWIN, K. (1951). Field theory in social science; selected theoretical papers. D. Cartwright (ed.). New York: Harper \& Row.

MINATI, G. and COLLEN, A. (2009). Architecture as the Cybernetic Self-Design of Boundary Conditions for Emergent Properties in Human Social Systems, Cybernetics \& Human Knowing, 16, (1-2):101-123.

PESKIN, M. E. and SCHROEDER, Daniel V. (1995). An Introduction to Quantum Fields. Princeton: Princeton University Press.

MARSHALL, S. (2008). Cities, Design and Evolution. Routledge - Taylor and Francis Group.

WEINSTOCK, M. (2010). The Architecture of Emergence: The Evolution of Form in Nature and Civilisation. London: Wiley.

\section{WEB RESOURCES}

Space Syntax Laboratory, available from http://www.spacesyntax.org/

Cozens, P.M., Saville, G. and Hillier, D. (2005). Crime prevention through environmental design (CPTED): a review and modern bibliography. Property Management, Emerald, Vol. 23 No. 5, pp. 328-356 available from http://www.emeraldinsight.com/journals.htm?articleid=1529573\&show=html 